\title{
Necrotizing Encephalomyelopathy of Leigh
}

\section{Neuropathological Findings in 8 Cases}

\author{
A. D. DAYAN, B. G. OCKENDEN, $\star$ and L. CROME \\ From the Department of Neuropathology The Hospital for Sick Children, Great Ormond Street; Institute of Child \\ Health, London; and Department of Pathology, Queen Mary's Hospital for Children, Carshalton, Surrey
}

Dayan, A. D., Ockenden, B. G., and Crome, L. (1970). Archives of Disease in Childhood, 45, 39. Necrotizing encephalomyelopathy of Leigh: neuropathological findings in 8 cases. Eight patients with necrotizing encephalomyelopathy are reported.

Lesions were found only in the central nervous system. The principal sites affected were the caudate nuclei, putamina, periaqueductal tissues, tegmentum, and structures in the floor of the IVth ventricle. Lesions were also found in the centrum ovale, cerebellum, and the grey and white matter in the spinal cord. The histological findings were of spongy rarefaction, scarring, and excessive vascularity.

The pattern of inheritance of necrotizing encephalomyelopathy suggests that it is due to an autosomal recessive gene. Though the disease closely resembles the encephalopathy of thiamine deficiency, morphological and biochemical evidence suggests that this is not a direct aetiological factor. It is possible that the condition is due to a disorder of lipoic acid metabolism, perhaps at a step near the thiamine-dependent stage of carbohydrate metabolism.

'Subacute necrotizing encephalomyelopathy' was the term first used by Leigh (1951) in describing a 7-month-old boy, who died after six weeks of increasing lethargy and generalized spasticity. At necropsy bilateral symmetrical necrotic lesions were found in the brain-stem and central grey matter of the medulla. Since his account some 50 similar cases have been reported, many of them in sibs, and several hypotheses have been advanced about the aetiology of the disease.

We describe the pathological changes in 8 further patients, 2 of whom had affected brothers. 3 of our patients were sibs (Cases 1,2, and 3), and a clinical and biochemical account of this family has already been given by Clayton, Dobbs, and Patrick (1967). Case 1 has also been mentioned briefly by Crome and Stern (1967).

\section{Case Reports}

The clinical histories of the patients have been summarized separately, but the morbid anatomical

\footnotetext{
Received 7 July 1969.

^Present address: Department of Pathology, North Staffordshire Royal Infirmary, Stoke-on-Trent.
}

findings were so stereotyped that they have been combined in the section 'Pathological Observations'.

Case 1. The second male child of healthy unrelated parents, who was born and developed normally until the age of 13 months, when he had a brief illness associated with vomiting and convulsions. After this he deteriorated and within two months was too weak to raise his head, and he ceased to speak. He continued to have periodic bouts of vomiting, pyrexia, and acute dehydration from which he would recover quickly on treatment with copious oral fluids. Repeated investigations, including EEG, failed to reveal any significant abnormality apart from persistently low plasma alkaline phosphatase levels. Repeated air encephalograms showed that cerebral atrophy developed over the next year.

Short attacks of eye rolling movements and CheyneStokes respiration occurred as he continued to deteriorate. He died from bronchopneumonia aged 3 years and 7 months.

Family history. The parents are healthy and unrelated, and there was no previous history of neurological illness in either family. The eldest child, a boy aged 10 years, is clinically well; the second is the propositus; the third, a girl, is Case 2; and the fourth, a girl, is Case 3. 
Case 2. The younger sister of Case 1 was born and seemed to develop normally until the age of 10 months. She then began to suffer from episodic vomiting and muscular weakness; mental deterioration followed. Within a short time she could no longer walk, was soon unable to hold up her head, and became mute. There was a close resemblance clinically between her illness and that of her brother, following whose death a diagnosis of necrotizing encephalomyelopathy was made. Because of the similarity of this disorder to Wernicke's encephalomyelopathy, further investigations of her carbohydrate metabolism were undertaken (Clayton et al., 1967), and greatly increased blood lactate and pyruvate levels were found. She also had a persistently low plasma alkaline phosphatase. Despite her very severe brain damage attempts were made to correct these biochemical abnormalities. Sequential therapy with thiamine, thiamine pyrophosphate, D-penicillamine, $a$-lipoic acid, and vitamin B12 had no appreciable effect clinically or chemically. She continued to have episodes of vomiting, dehydration, and acidosis, and short attacks of eye rolling and Cheyne-Stokes respiration. She died aged 3 years and 10 months.

Case 3. The fourth child and youngest sister of Cases 1 and 2 seemed normal until the age of 10 months when her parents thought she was developing symptoms similar to those of her brother and sister. On examination the only abnormality found was a mild generalized hypotonia. Extensive biochemical investigations revealed an increased blood pyruvate concentration of $2.25 \mathrm{mg} . / 100 \mathrm{ml}$., and blood lactate levels of up to $16 \mathrm{mg} . / 100 \mathrm{ml}$. In view of the severe biochemical disorder she was treated like her sister, and during the next year courses of oral thiamine, thiamine pyrophosphate, and D-penicillamine were given without effect. Her hypotonia increased, episodic vomiting occurred, and her condition deteriorated slowly. At 2 years and 4 months therapeutic trials of lipoic acid and vitamin B12 were begun (Clayton et al., 1967). On lipoic acid alone she appeared to improve and the blood pyruvate level gradually fell to normal. After various difficulties with the therapy she was finally treated by lipoate injections. By the age of 5 years, though still severely handicapped, she was very happy, continent by day, had limited verbal comprehension, and her episodes of vomiting or acidosis had ceased. At $6 \frac{1}{2}$ years of age, following what was thought to be an upper respiratory tract infection, her condition suddenly deteriorated and she died.

Case 4. A girl, the only child of healthy unrelated parents, was admitted to hospital at 4 months because of failure to thrive and diarrhoea. She was thought to be blind and deaf and weighed $3.6 \mathrm{~kg}$. (birthweight 2.6 kg.). Routine laboratory investigations were normal. At this time she began to have occasional grand mal seizures. During the next two months, the child became stuporose, and the character of the fits changed to episodes of apnoea followed by slow irregular grunting respirations. She died, aged months, after a series of apnoeic attacks.

Case 5. A boy, the only child of healthy unrelated parents, was born and developed normally until fo months of age, when he began to vomit effortless after meals and ceased to thrive. On examination at 15 months he was physically and mentally retardes presenting generalized hypotonia and athetoid move्ष ments of his upper limbs. Because of persistent acidosis (serum bicarbonate $15 \mathrm{mEq} / \mathrm{l}$.) he was treated with Albright's solution on several occasions, witto some physical but no mental improvement. At is months he suddenly lapsed into coma with infrequerdo grunting respirations, and died shortly afterwards.

Case 6. The early history of this boy, the onf child of unrelated parents, is unknown, but he was sakel to be of low intelligence. At 6 years he was found to have weakness of the legs, and 3 years later weakness $\delta P$ the hands was noticed. By the age of 11 years he had spastic paraplegia. At 12 years he developed 'whooping cough'; vomiting occurred, with paroxysms of coughing and simultaneously his arms, legs, and trunk became weaker. During the next few months the weaknesi became more pronounced, his speech became slurref respirations laboured, and he developed bilateral ptosi He suddenly became drowsy and was admitted to hos pital, where he was found to have pale optic disc $\overrightarrow{8}$ nystagmus, and a metabolic acidosis. He died f嗮 pulmonary oedema.

Case 7. This girl, the second child of unrelate parents, was found at 3 months to be generally retarde She was unable to hold up her head, did not follow lights, and had increased muscle tone. All laborator investigations were normal. An EEG showed occasiona spikes in the left frontal region. She developed verf slowly until 10 months when she suddenly became cyanosed and died 24 hours later.

Family history. At 6 months of age her elder brothet had had pale optic discs, and a diffuse abnormality ợ electroencephalography. $\mathrm{He}$ had been diagnosed microcephalic, lethargic, and mentally retarded when. 3 years old. Later he began having 'blue turns' ang suddenly collapsed and died a month later.

At necropsy his brain and viscera appeared normaj macroscopically but were not examined in detail.

Case 8. This girl, the third child of healthy un: related parents, was born and developed normalify until the age of 10 months when she began to vomit 3 to 4 times daily. No abnormal physical signs we: found at that time. In particular, the optic fundi and discs were normal, there was no evidence of any ins coordination, and her reflexes were brisk. Further investigations showed a consistently raised CSF prote level and mild acidosis. During the following yeaf she continued to have infrequent episodes of vomiting and became hypotonic. Later her parents noticed 
that she cried a lot, was unsteady, and had episodes of 'gasping respirations'. On re-examination she was found to have increased limb tone, slow vertical nystagmus, and advanced bilateral optic atrophy. She continued to deteriorate and died at the age of 2 years and 3 months.

Family history. The parents were healthy and unrelated. Their first child, a boy, was born and developed normally until 7 months of age when he developed episodic vomiting which lasted for 8 months. He then deteriorated physically, became hypotonic, could no longer stand, and developed nystagmus and ataxia. He had prolonged screaming attacks and his speech became slurred though he remained mentally alert. The optic discs were pale and there was marked vertical nystagmus. An air encephalogram revealed mild ventricular dilatation and widening of frontal sulci suggestive of mild cerebral atrophy. His condition continued to deteriorate slowly, he became mute, developed bilateral optic atrophy, a squint, dysphagia, facial weakness, and gross hypotonia. Eventually he died at $3 \frac{1}{2}$ years of age. At necropsy an old superior sagittal sinus thrombosis was found. The brain was said to be normal externally, but was not examined further.

The second child, a girl now 14 years old, is well.

\section{Pathological Observations}

The main neuropathological lesions, which were almost always symmetrical, were brown or grey areas of softening of spongiform degeneration. Their appearances and distribution were stereotyped and were almost diagnostic of necrotizing encephalomyelopathy (NE). Of the basal ganglia, the caudate nuclei and putamen were most frequently and most severely damaged, often with almost total destruction of their substance (Fig. 1) and replacement by a greyish ragged network of fibres and debris. They were spared only in Cases 4 and 7. The globus pallidus was less often involved. The thalamus contained a small lesion in

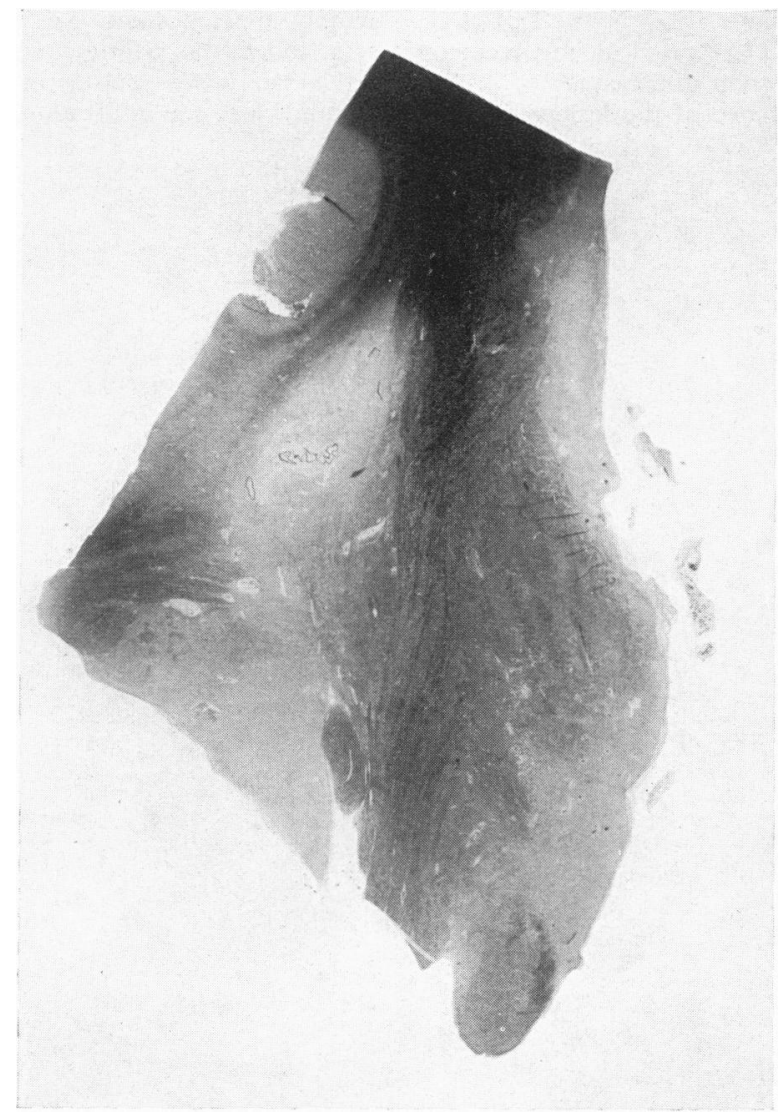

FIG. 1.-Case 6. Degeneration of caudate nucleus and putamen. Mamillary body appears normal. (H. and E. $\times 3 \cdot 5$.) 
only one patient (Case 3), and the mamillary bodies were normal in all our patients. In Cases 5 and 6 there was demyelination of the centrum ovale and diffuse gliosis. Destruction of centrally situated axons with gliosis was found in the optic nerves of Cases 2, 3, 6, and 8 (Fig. 2). Within the brain-stem, lesions were denser and more extensive. Severe lesions of the tectum, usually involving also the periaqueductal grey matter, were present in 4 patients (Cases $1,2,3$, and 5). The substantia nigra was affected in 6 cases (Cases 1, 2, 3, 6, 7, and 8). In all cases there were brown spongiform lesions in the tegmentum of the pons (Fig. 3) and structures continuous with it caudally beneath the floor of the IVth ventricle. In the medulla, destruction and rarefaction were extensive, involving the inferior olives in all cases and the superior olives alone in one case (Case 6). The central grey matter of the reticular formation was severely affected in 5 patients (Cases 1, 2, 3, 4, and 6). Of our 8 patients the dentate and roof nuclei of the IVth ventricle were damaged in 2 (Cases 1 and 6) (Fig. 4), and in 3 (Cases 5, 6, and 8) the cerebellar cortex contained sclerotic shrunken folia (Fig. 5). The spinal cord showed discoloration and lesions in the posterior columns (Fig. 6) in all cases in which it was examined. Microscopical involvement of the anterior horns was present in 2 cases.

The microscopical appearance of the lesions seemed

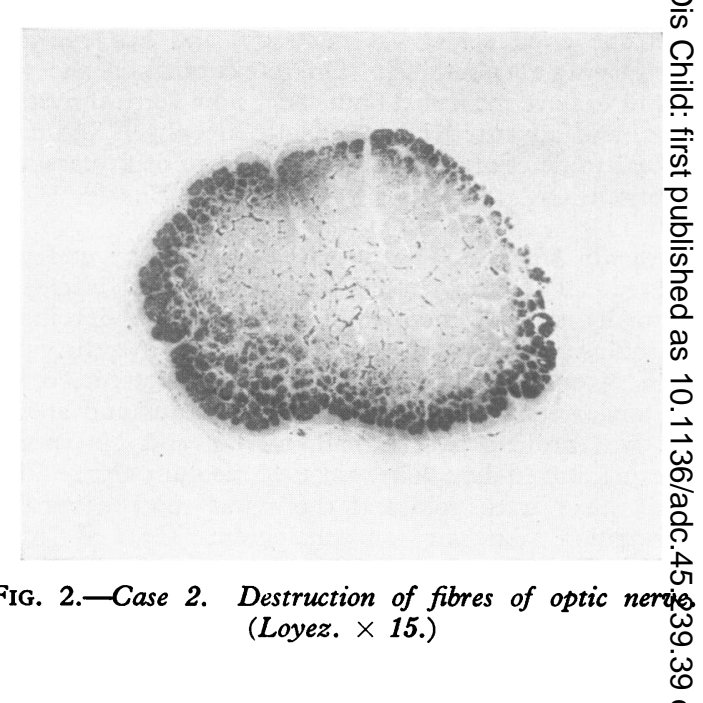

to vary with their duration. Pathologically, the most acutely affected areas, e.g. the inferior olives in Cases 1,3 , and 6 , the pontine tegmentum in Case 4 , or tha cerebellar white matter in Case 3, showed foci of mononuclear cell infiltration, including activated micr

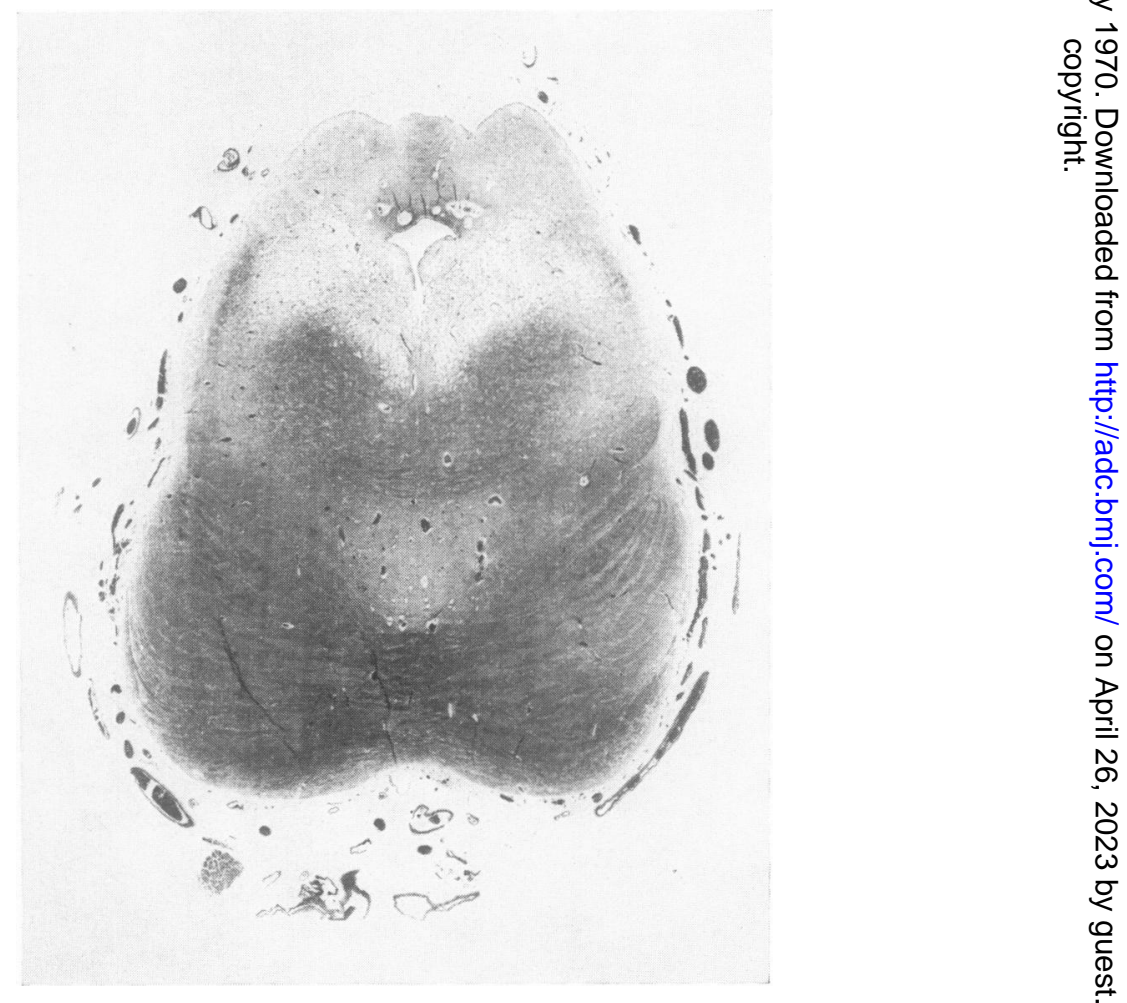

FIG. 3.-Case 3. Widespread damage to inferior corpora quadrigemina and pontine tegmentum. (H. and E. $\times 6$. 


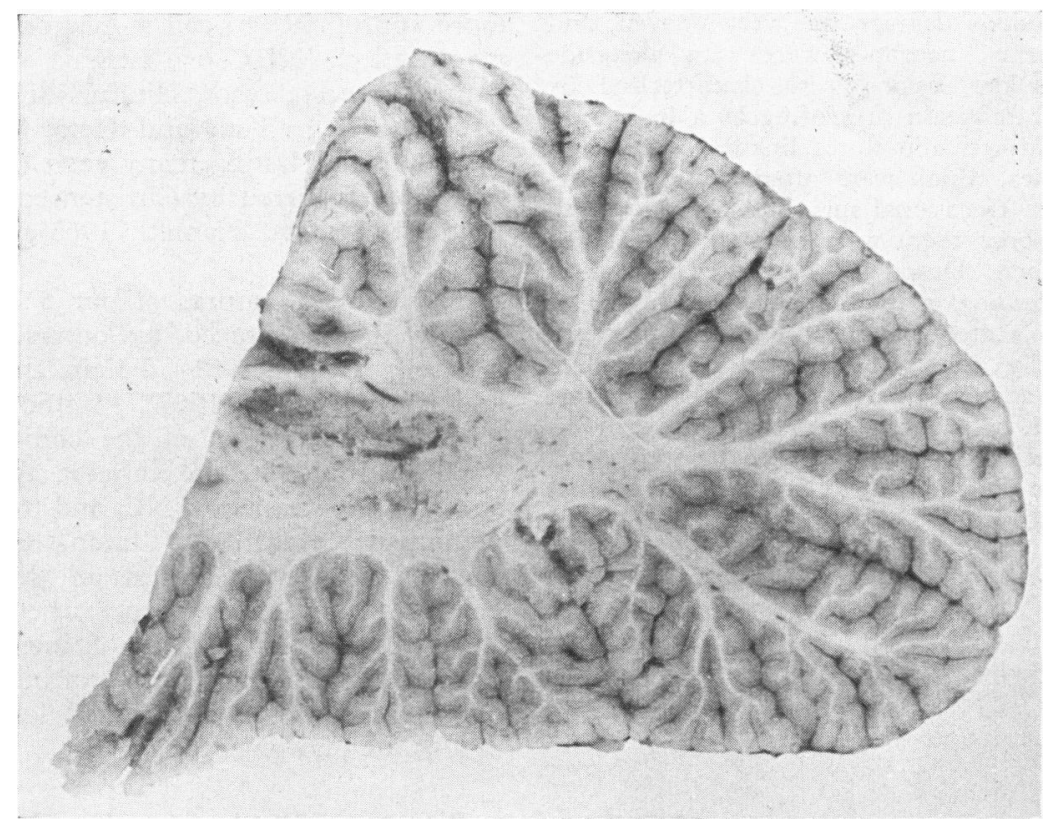

FIG. 4.-Case 1. Destruction of dentate nucleus and adjacent white matter.

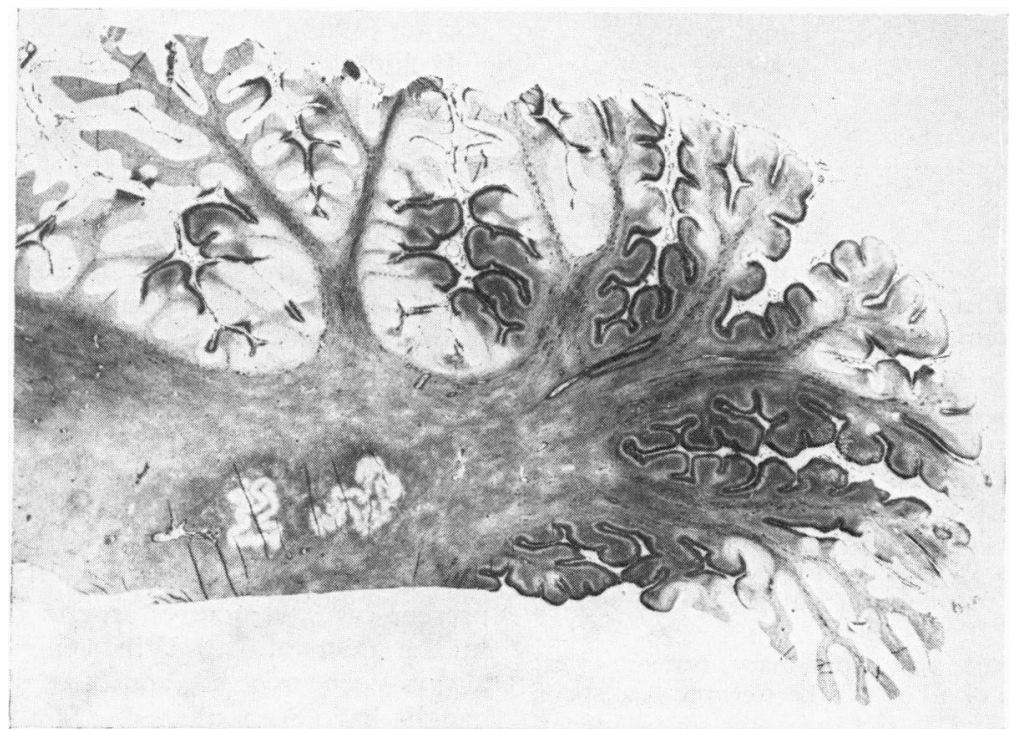

FIG. 5.-Case 6. Scattered gliotic folia and diffuse gliosis of cerebellar white matter. $($ Holzer. $\times 5$.

glia apparently reacting to necrotic neurones and glial cells. Neuronophagia was seen at these sites, and there was cuffing of blood vessels by reactive cells, engorgement of capillaries and, sometimes, small haemorrhages. Reactive astrocytes were commonly present in such areas. Sometimes they were binu- cleated, and a few Alzheimer type II cells were found. Oedema also occurred, producing a sponge-like appearance of the neuropil, with separation of its constituent fibres. In affected areas there was damage to the nerve fibres, which appeared sometimes to have lost their myelin sheaths before degeneration of the axons. 
Even in acute lesions damage was very uneven, and histologically normal neurones were seen alongside necrotic ones. Older lesions were characterized by marked spongy rarefaction presenting as a loose network of glial and reticulin fibres linking dilated and tortuous capillaries, which were often present in excessive numbers. Occasional surviving neurones with variable gliosis about them were seen in the rarefied and necrotizing foci. Despite the frequency of haemorrhages in acute lesions, gliotic foci contained little iron pigment. Both acutely and chronically damaged areas were usually quite well demarcated and often were confined to anatomical structures, e.g. the caudate or dentate nuclei, or a cranial nerve nucleus. In the present series, lesions of the basal ganglia were older than those in the pons and medulla, probably because the latter were lethal.

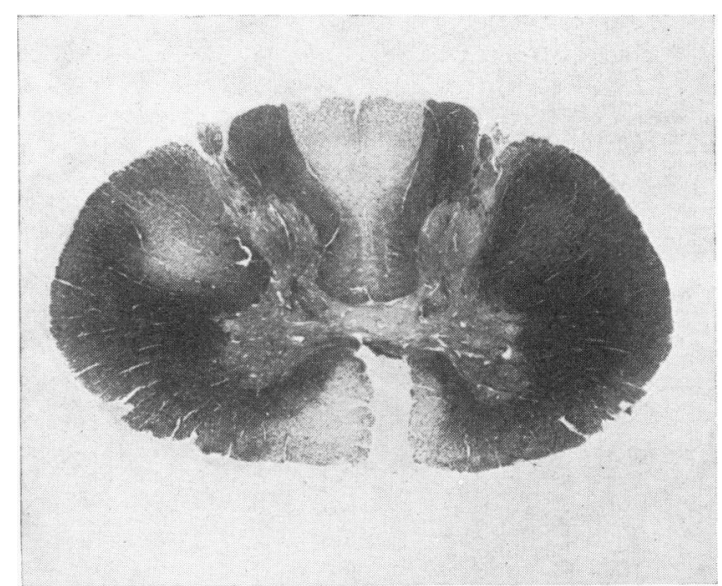

Fig. 6.-Case 3. Severe loss of fibres from posterior columns and lateral and anterior corticospinal tracts of spinal cord. (Heidenhain. $\times 8$.)

No lesions were found in the adrenal medulla, autonomic ganglia, or myenteric plexuses of the intestines in Cases $1,2,3,5$, and 7 in which they were examined. Sudan black-stained, thick frozen sections (Cavanagh, Passingham, and Vogt, 1964) of skeletal muscle from Cases 1, 2, and 3 were examined, and no damage was seen to motor nerves or muscle spindle innervation.

Bronchopneumonia and pulmonary oedema were found in the lungs of all cases; the sternum was spoon shaped in Cases 2 and 3 ; and there was severe inflammation of the lower third of the oesophagus in Cases 5 and 7. No other pathological changes were found in the viscera or endocrine glands of any of the patients.

\section{Discussion}

About 50 cases have been reported of the disease originally described by Leigh (1951) as 'subacute necrotizing encephalomyelopathy'. It now seems more appropriate to call it 'necrotizing encephalomyelopathy' (NE), or 'Leigh's encephalomyelopathy', as acute cases, clinical illness lasting only 24 hours (e.g. Tom and Rewcastle, 1962), and chronic forms, lasting many years (e.g. our Case 6, and those reported by Christensen, Melchior, and Plum, 1963; and Namiki, 1965), have also been described.

The clinical features of our 8 cases resembled closely those reported by others, including, for example, Leigh (1951), Feigin and Wolf (1954), and Clayton et al. (1967). Without entering into a detailed discussion of the clinical features, we wish to emphasize the variable age of onset and speed of progression of NE, and the predominance of unusual features of brain-stem disorders at some stage during almost all the illnesses, e.g. episodic vomiting, apnoea, varieties of CheyneStokes respiration. It is of interest, though of uncertain significance, that 2 of our patients had a deformed sternum, and 3 had low plasma levels of alkaline phosphatase.

Review of literature. Details of many of the cases reported previously have been outlined by Crome and Stern (1967), Guazzi et al. (1968), and Richter (1968).

Including the present series, approximately $60 \%$ of the patients have been male. The age of onset of clinical symptoms and signs has varied from a few weeks (Leigh, 1951) to the early teens (e.g. Christensen, Melchior, and Plum, 1963; Tuthill and Henn, 1964; Peterson and Alvord, 1964). The duration of the illness has ranged from 2 months to 10 years, and the age at death from 4 months to 15 years. No close correlation has been found between the age of onset of symptoms and duration of the disease, nor between duration and distribution of the lesions except for the preponderance of acute brain-stem damage in patients dying after short illnesses.

The anatomical distribution of the lesions is limited and is summarized in Fig. 7. As in the present cases, structures around the aqueduct and in the floor of the IVth ventricle have almost always been involved, and often some of the basal ganglia have been affected. Similarly, the inferior olives, cerebellar cortex, and dentate nucleus have often been damaged. The cerebral cortex has been less often involved. Ule (1959-Case 1) described loss of cortical neurones, and Tom and Rewcastle (1962) uniquely reported vacuoles in the deeper layers of the cerebral cortexiand arterial calcification. The 'geographical' necroses in the cerebral cortex noted by Richter (1957) in his 
A
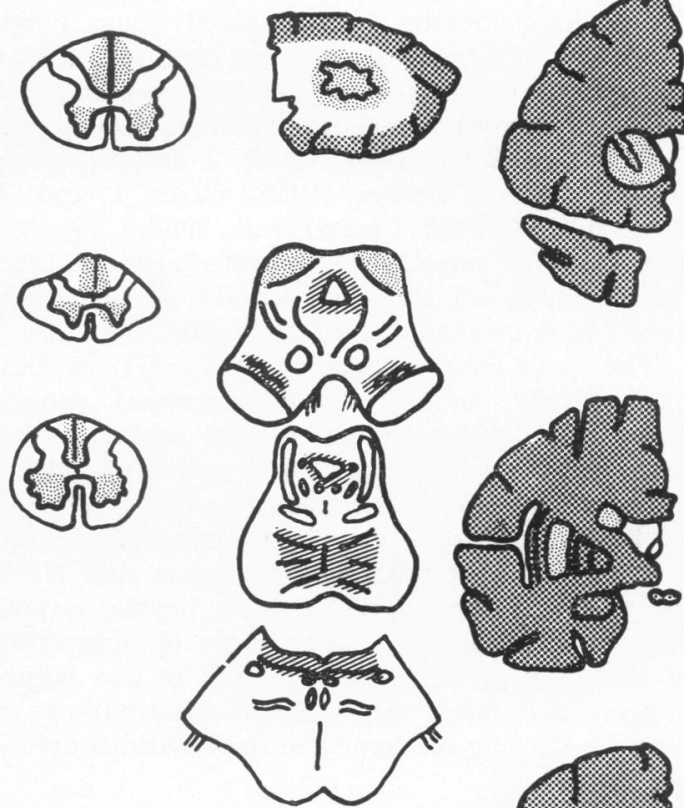

PERCENTAGE AFFECTED
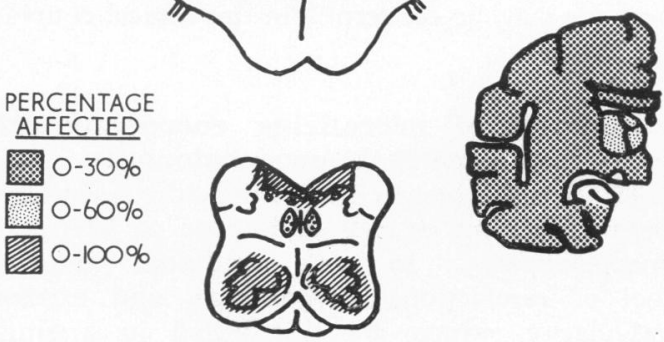
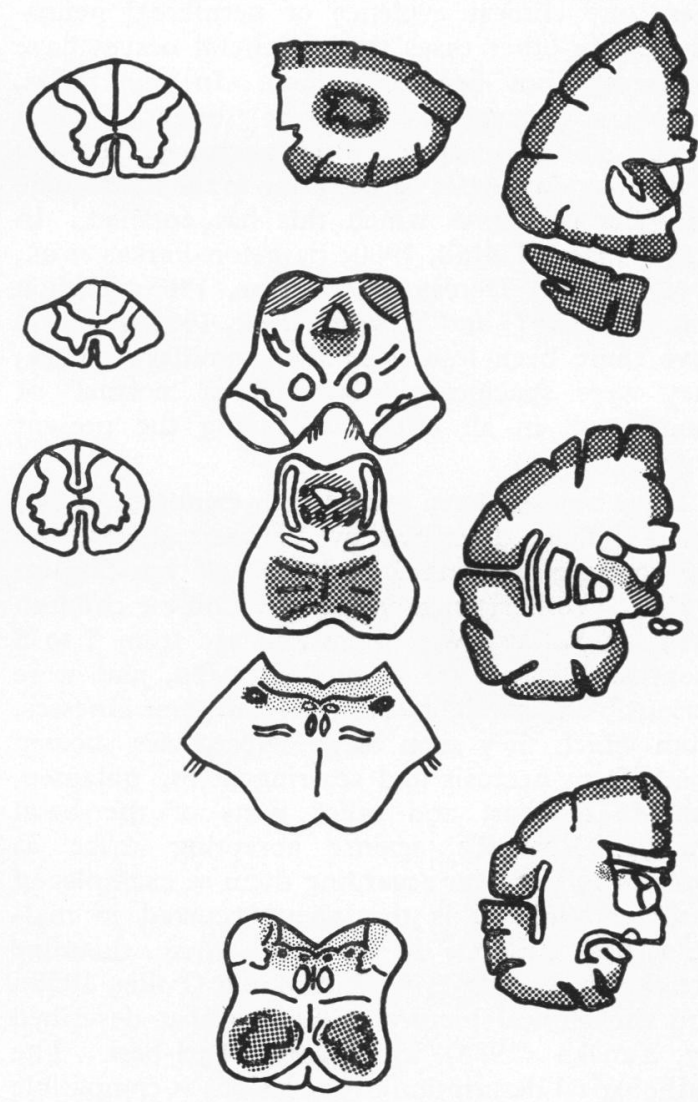

FIG. 7.-Diagram showing distribution of cerebral lesions in (a) necrotizing encephalomyelopathy, (b) Wernicke's encephalopathy. Shading represents frequency of occurrence of damage in areas shown.

Case 2 are, perhaps, related to the episodes of respiratory failure from which the patient suffered. It is possible that the cortical lesions in the cases of Guazzi et al. (1968) were also due to similar secondary causes. Diffuse damage to the cerebral white matter seems rare and has been reported only by Garcin, Gruner, and Godlewski, 1956; Wohlwill and Paine (1958, Case 1); Procopis, Turner, and Selby, 1967; and Guazzi et al. (1968, Case 3); and was present in our Case 6. Damage to the optic nerves, consisting of central demyelination and gliosis and, sometimes, loss of axons and excessive vascularity, have been found in 20 patients. In the present Case 4 , and in the first patient of Worsley et al. (1965), the lateral geniculate bodies were also scarred. Typical lesions have been described in the white matter or anterior horns of the spinal cord in almost half the patients (e.g. Leigh, 1951; Worsley et al., 1965; Guazzi et al., 1968). The patchy nature of the damage in some patients has been compared to the lesions found in vitamin B12 deficiency, but a more common finding has been diffuse damage to entire tracts akin to that of the system degenerations (Guazzi et al., 1968). Reye (1960), in describing 4 cases of NE, was the first to notice lesions in the peripheral nervous system. In all his cases there was said to be 'demyelination' of the peripheral nerves, though it is not clear whether this was a true segmental demyelination or Wallerian degeneration. Namiki (1965) reported a single case in which the peripheral nerves showed probable Wallerian degeneration, and Guazzi et al. (1968) reported segmental demyelination in the sciatic nerve of their Case 3, without describing how it was demonstrated and without illustrating this specific 
type of lesion. In none of these patients was there any clinical evidence of peripheral neuropathy. In other cases the peripheral nerves have apparently not been examined. In our series, peripheral nerve lesions were sought without success in tissue stored after necropsy. Failure to find any damage is perhaps due to the inadequate sampling of nerves which this has entailed. In only 5 cases (Tuthill, 1960; Bargeton-Farkas et al., 1964); Eiben, Dooley, and Stowe, 1965; Yashon and Jane, 1967; and Worsley et al., 1965-Case 1) have there been lesions in the mamillary bodies; they were specifically described as 'normal' or 'unaffected' in all others, including the present series.

Some authors have accepted as examples of NE the 4 infants described by Verhaart (1938), and the young girl reported by Poser and van Bogaert (1960). Verhaart's cases were all Chinese children living in Batavia, who ranged in age from 5 to 8 months. They were being breast-fed, and were seriously underweight at the onset of their illnesses, from which they soon died. Necropsies showed spongiform necrosis and scarring in the putamen, caudate nucleus, and other parts of the basal ganglia. Evidence against accepting these as cases of $\mathrm{NE}$ and for regarding them as examples of cerebral beri-beri is that they occurred in malnourished children in an area where thiamine deficiency syndromes were common (Follis, 1958), and the clinical picture resembled that described by Tanaka (1934) in infantile beri-beri. The pathological description of the lesions is compatible with either disease and is ambiguous in that the state of the corpora mamillaria is not mentioned. Poser and van Bogaert's (1960) patient showed an unusual pattern of 'tigré' demyelination, spongiform degeneration of the centrum ovale, and necrosis of the tegmentum of the pons. The lesions in the white matter were unlike any reported in NE and the basal ganglia were normal, whereas in NE one or more of these structures has usually been damaged. These differences, as well as the lack of capillary or mesenchymal proliferation specifically mentioned by these authors, makes this case unlikely to have been one of NE. On similar morbid anatomical grounds it is possible to exclude the cases of striatal necrosis reported by Hawke and Donohue (1951), Wohlwill and Paine (1958), and Mathieson and Olszewski (1960), and very probably those of Marinesco and Draganesco (1929). The children described by Paterson and Carmichael (1924) may well have suffered from NE as the clinical and pathological account is compatible with this retrospective diagnosis.
Familial incidence. Strong evidence favouring a genetic factor in the aetiology of necrotizing encephalomyelopathy has appeared since Feigin and Wolf (1954) recorded the first cases in a brother and sister. Of the patients in whom the diagnosis has been proved histologically, 5 are sets of sibs (Feigin and Wolf, 1954, Cases 2 and 3; Ebels, Blokzijl, and Troelstra, 1965, Cases 1 and 2; Worsley et al., 1965; Guazzi et al., 1968, Cases 1, 2, and 3 of this series). If clinical diagnoses, often retrospective, are also accepted, 15 of 34 families have had more than one affected child.

The male/female incidence is $1 \cdot 5 / 1$ in both histologically and clinically diagnosed groups. In 3 of 31 families the parents are related, with a first cousin relationship in 2 (Richter (1957) includes a patient whose maternal uncle is also said to have died from an illness resembling NE.)

The pattern of inheritance suggests that NE is due to an autosomal recessive gene, but the variable age of onset and the diverse rates of progression of the cases, even those occurring in one family, suggest that other factors, environmental or inherited, may be concerned in the clinical course of the disease.

Relation of necrotizing encephalomyelopathy to Wernicke's encephalopathy. Leigh (1951) was the first to discuss the close resemblance between lesions of NE and those of Wernicke's ? encephalopathy. In both conditions there are foci of rarefaction, haemorrhage, and excessive vascularity, which are distributed in a similar fashion throughout the nervous system. A major pathological difference between the two conditions is the almost invariable involvement of the mamillary bodies in Wernicke's disease, and their very rare involvement in NE (see above). The widespread demyelination sometimes reported in NE has not been reported as a feature of Wernicke's encephalopathy. The typical distribution of lesions in the latter disease is shown diagrammatically in Fig. $7 \mathrm{~b}$, which is based on the reports of Gamper (1928), Campbell and Biggart (1939), Riggs and Boles (1944), and Malamud and Skillicorn (1956). Though there are pathological differences between the two conditions, individual features are inconstant and are unreliable as criteria for differentiating individual cases. However, in no case of NE has there been any evidence of disorders which might cause the thiamine deficiency which is responsible for Wernicke's encephalopathy, e.g. chronic alcoholism. Other features of thiamine deficiency such as cardiac failure or aphonia have also been absent. The pattern of autosomal recessive inheritance 
found in NE also is not compatible with a dietary vitamin deficiency.

The failure to respond to pharmacological doses of thiamine in our Cases 2 and 3 (and other reported cases), and the normal concentrations of thiamine found in the blood of Case 2, provide further evidence against the pathogenetic role of simple thiamine deficiency (Clayton et al., 1967). Conclusive proof that there is no connexion between an abnormality of thiamine metabolism and NE must await discovery of the pathogenic biochemical lesion of NE.

Pathogenesis. The morbid anatomical similarities between NE and Wernicke's encephalopathy, and the frequent observation of raised levels of pyruvate and lactate in the blood of patients with $\mathrm{NE}$, have led to suggestions that the biochemical lesions in the two diseases might be in closely related metabolic reactions. This has been supported by the observation of Clayton et al. (1967) that the present Case 3 responded temporarily to treatment with lipoic acid, a compound involved in the pyruvate oxidase system at a stage immediately preceding that dependent on thiamine. (Some beneficial effects were also observed from the use of lipoic acid in the case of Hommes, Polman, and Recrink (1968).) Though there is no evidence of over-all inhibition of this complex of enzymatic reactions in the brain in $\mathrm{NE}$, it is possible that both the similarities and differences between it and Wernicke's encephalopathy are due to a lesion in consecutive biochemical reactions whose effects are modified by the relative biological importance of this and associated reactions at different sites in the brain. This hypothesis remains speculative because it lacks direct biochemical support. Worsley et al. (1965) found abnormal red cell glucose metabolism in their case of NE, but did not characterize the defect. The patient described by Hommes et al. (1968), who had a very low level of pyruvate carboxylase in the liver and persistent hypoglycaemia, must be regarded as atypical as no other examples of NE have been reported with low blood sugars. They were normal in our patients.

The complex nature of the metabolic and pathological responses of the nervous system to a lack of thiamine, and, by analogy, to a disturbance of lipoic acid metabolism, are illustrated by the disorder 'cerebro-cortical necrosis of calves' (Innes and Saunders, 1962). The cerebral lesions found in this disease are very different from those classically described in thiamine deficiency, and yet there is now good evidence that it is due to an induced deficiency of this vitamin (Pill, 1967; Davies, Pill, and Austwick, 1968). As secondary factors may affect the timing and nature of the pathological lesions which finally appear in this and related diseases, it seems likely that there is a tortuous pathway between disordered metabolism of lipoic acid and the widespread damage to the brain found in NE.

We are grateful to Dr. B. E. Clayton, Dr. R. H. Dobbs, Dr. N. E. France, Professor H. Urich, Sir Wilfrid Sheldon, Dr. D. A. J. Williamson, Dr. J. Wilson, and the late Dr. S. Yudkin for permission to quote details of their patients, and for their support, to the Joint Research Board of The Hospital for Sick Children.

\section{REFERENCES}

Bargeton-Farkas, E., Cochard, A. M., Brissaud, H. E., Robain, O., and Le Balle, J. C. (1964). Encéphalopathie infantile familiale avec nécrose bilatérale et symétrique des corps striés. Fournal of the Neurological Sciences, 1, 429.

Campbell, A. C. P., and Biggart, J. M. (1939). Wernicke's encephalopathy (polioencephalitis haemorrhagica superior): its alcoholic and non-alcoholic incidence. Fournal of Pathology, $48,245$.

Cavanagh, J. B., Passingham, R. J., and Vogt, J. A. (1964). Staining of sensory and motor nerves in muscles with sudan black $B$. fournal of Pathology, 88, 89.

Christensen, E., Me!chior, J. C., and Plum, P. (1963). Infantile chronic necrotizing encephalopathy. Acta Neurologica Scandinavica, 39, Suppl. 4, 291.

Clayton, B. E., Dobbs, R. H., and Patrick, A. D. (1967). Lcigh's subacute necrotizing encephalopathy: clinical and biochemical study, with special reference to therapy with lipoate. Archives of Disease in Childhood, 42, 467.

Crome, L., and Stern, J. (1967). The Pathology of Mental Retardation. p. 314. Churchill, London.

Davies, E. T., Pill, A. H., and Austwick, P. K. C. (1968). The possible involvement of thiamine in the aetiology of cerebrocortical necrosis. Veterinary Record, 83, 681.

Ebels, E. J., Blokzijl, E. J., and Troelstra, J. A. (1965). A Wernickelike encephalomyelopathy in children (Leigh), an inborn error of metabolism ? Report of five cases with emphasis on its familial incidence. Helvetica Paediatrica Acta, 20, 310.

Eiben, R. M., Dooley, J. P., and Stowe, S. M. (1965). Subacute necrotizing encephalopathy in infancy. (Abstr.) Neurology, $15,293$.

Feigin, I., and Wolf, A. (1954). A disease in infants resembling chronic Wernicke's encephalopathy. Fournal of Pediatrics, 45, 243.

Follis, R. H., Jr. (1958). The pathology of endemic beriberi. Federation Proceedings, 17, Suppl. 2, 20.

Gamper, E. (1928). Zur Frage der Polioencephalitis haemorrhagica der chronischen Alkoholiker. Anatomische Befunde beim alkoholischen Korsakow und ihre Beziehungen zum klinischen Bild. Deutsche Zeitschrift für Nervenheilkunde, 102, 122.

Garcin, R., Gruner, J., and Godlewski, S. (1956). Spongiose disséminé de l'encéphale évoluant cliniquement par poussées chez un enfant malgache. Ses rapports éventuels avec l'encéphalopathie subaiguë de Wernicke. Revue Neurologique, 85, 273.

Guazzi, G. C., Martin, J. J., Brucher, J. M., Taper, H. S., Macken, J., Neetens, A., and van Haegenborgh, J. (1968). Sur l'importance de l'atteinte vasculaire et de la dystrophie gliale dans l'encéphalomyélopathie nécrosante de Leigh. Etude de deux familles et de trois observations anatomiques. Fournal of the Neurological Sciences, 7, 357.

Hawke, W. A., and Donohue, W. L. (1951). Bilateral symmetrical necrosis of the corpora striata. Report of a fatal case and reference to a possible syndrome of the corpora striata. Fournal of Nervous and Mental Disease, 113, 20.

Hommes, F. A., Polman, H. A., and Reerink, J. D. (1968). Leigh's encephalomyelopathy: an inborn error of gluconeogenesis. Archives of Disease in Childhood, 43, 423. 
Innes, J.-R. M., and Saunders, L. Z. (1962). Comparative Neuropathology, p. 392. Academic Press, New York and London.

Leigh, D. (1951). Subacute necrotizing encephalomyelopathy in an infant. Fournal of Neurology, Neurosurgery and Psychiatry, 14, 216.

Malamud, N., and Skillicorn, S. A. (1956). Relationship between the Wernicke and the Korsakoff syndrome. Archives of Neurology and Psychiatry, 76, 585.

Marinesco, G., and Draganesco, S. (1929). Contribution anatomoclinique à l'étude du syndrome de Foerster. Encéphale, 24, 685.

Mathieson, G., and Olszewski, J. (1960). Central pontine myelinolysis with other cerebral changes. Neurology, 10, 345.

Namiki, H. (1965). Subacute necrotizing encephalomyelopathy. Case report with special emphasis on associated pathology of peripheral nervous system. Archives of Neurology, 12, 98.

Paterson, F., and Carmichael, E. A. (1924). A form of familial cerebral degeneration chiefly affecting the lenticular nucleus. Brain, 47, 207.

Peterson, H. deC., and Alvord, E. C., Jr. (1964). Necrotizing encephalopathy with predilection for the brainstem. Subacute infantile and chronic juvenile familial forms. Transactions of the American Neurological Association, 89, 104.

Pill, A. H. (1967). Evidence of thiamine deficiency in calves affected with cerebrocortical necrosis. Veterinary Record, $81,178$.

Poser, C., and van Bogaert, L. (1960). Leuco- et polio-encéphalopathies symétriques nécrosantes. Reque Neurologique, 103, 2.

Procopis, P. G., Turner, B., and Selby, G. (1967). Subacute necrotizing encephalopathy in an acidotic child. fournal of Neurology, Neurosurgery and Psychiatry, 30, 349.

Reye, R. D. K. (1960). Subacute necrotizing encephalomyelopathy. fournal of Pathology, 79, 165.

Richter, R. B. (1957). Infantile subacute necrotizing encephalopathy with predilection for the brain-stem. Fournal of Neuropathology and Experimental Neurology, 16, 281.

(1968). Infantile subacute necrotizing encephalopathy (Leigh's disease): its relationship to Wernicke's encephalopathy. Neurology, 18, 1125.
Riggs, H. E., and Boles, R. S. (1944). Wernicke's disease: clinical and pathological study of $\mathbf{4 2}$ cases. Quarterly fournal of Studies on Alcohol, 5, 361.

Tanaka, T. (1934). So-called breast milk intoxication. American Fournal of Diseases of Children. 47, 1286.

Tom, M. I., and Rewcastle, N. B. (1962). Infantile subacute necrotizing encephalopathy. Neurology, 12, 624.

Tuthill, C. R. (1960), Der morphologische Wernicke-Komplex in frühem Kindesalter (Familiăre Erkrankungen bei 7 Monate alten Zwillingen). Archiv für Psychiatrie und Nervenkrankheiten, 200, 520.

- and Henn, R. (1964). Wernicke-Syndrom im Kindesalter ohne Anzeichen von Mangelernährung. ibid., 205, 116

Ule, G (1959). Über eine der Wernickeschen Pseudoencephalitis entsprechende Encephalopathie bei Kindern. Virchows Archiv für pathologische Anatomie und Physiologie und für klinische Medizin, 332, 204.

Verhaart, W. J. C. (1938). Symmetrical degeneration of the neostriatum in Chinese infants. Archives of Disease in Childhood, 13, 225.

Wohlwill, F. J., and Paine, R. S. (1958). Progressive demyelinating leukoencephalopathy. Neurology, 8, 285.

Worsley, H. E., Brookfield, R. W., Elwood, J. S., Noble, R. L., and Taylor, W. H. (1965). Lactic acidosis with necrotizing encephalopathy in two sibs. Archives of Disease in Childhood, 40, 492.

Yashon, D., and Jane, J. A. (1967). Subacute necrotizing encephalomyelopathy of infancy and childhood. Fournal of Clinical Pathology, 20, 28.

Correspondence to Dr. A. D. Dayan, Department of Neuropathology, The Hospital for Sick Children, Great Ormond Street, London W.C.1. 